Научная статья

УДК 338.984

DOI 10.18101/2304-4446-2020-4-102-110

\title{
К ВОПРОСУ ОЦЕНКИ ПОТЕНЦИАЛА ПОВЫШЕНИЯ ЭФФЕКТИВНОСТИ УПРАВЛЕНИЯ В ОРГАНИЗАЦИЯХ ЖИЛИЩНОЙ СФЕРЫ
}

\author{
(C) Мавлютов Рамиль Ростемович \\ кандидат экономических наук, доцент, \\ Волгоградский государственный технический университет \\ Россия, 400005, г. Волгоград, пр. им. Ленина, 28 \\ ramil-2002@mail.ru
}

\begin{abstract}
Аннотация. Предпринимательская деятельность в жилищной сфере характеризуется низкой эффективностью управления. При этом последняя находится в ряду важнейших аспектов устойчивого развития бизнеса. В западной практике общим местом стало понимание того, что одним из важнейших аспектов успешного управления выступает контроллинг. В организациях жилищной сферы в России на настоящий момент наблюдается нехватка теоретических и практических знаний о контроллинге. В статье представлены результаты исследования, направленного на выявление текущего состояния контроллинга как основы оценки потенциала повышения эффективности управления в организациях жилищной сферы. В качестве объекта исследования выступили предприятия Волгоградской области, в том числе административного центра региона. Установлено, что современное понимание контроллинга мало распространено, и лишь в малом числе субъектов бизнеса нашли свою реализацию отдельные его элементы. При этом функции контроллинга возлагаются преимущественно на смежные подразделения.

Ключевые слова: организация; жилищная сфера; предпринимательская деятельность; бизнес; контроллинг; управление; эффективность; потенциал; опрос; информация.
\end{abstract}

\section{Для цитирования}

Мавлютов Р. Р. К вопросу оценки потенциала повышения эффективности управления в организациях жилищной сферы // Вестник Бурятского государственного университета. Экономика и менеджмент. 2020. № 4. С. 102-110.

Способность предвидения хозяйственной и коммерческой ситуации, обеспечение планомерного достижения поставленных целей, основной из которых является максимизация прибыли предпринимательской деятельности, составляют в своей совокупности искусство экономического управления хозяйствующим субъектом. Контроллинг представляет собой механизм этого искусства. При этом он ориентирован на будущее в координации с установленными целями и задачами по получению заданного результата. Контроллинг как концепция системного управления организуется чаще всего там, где имеется кризис управления либо результаты хозяйственной деятельности предприятия не соответствуют все повышающимся требованиям рынка [1]. При этом на современном этапе развития экономики России предпринимательская деятельность в жилищной сфере 
характеризуется низкой эффективностью, отсутствием системного подхода к управлению, малой инвестиционной привлекательностью.

Отечественное предпринимательское сообщество в последнее время проявляет все больший интерес к новым подходам в вопросах управленческой деятельности [2-4]. В связи с чем в целях выявления текущего состояния контроллинга как основы оценки потенциала повышения эффективности управления в организациях жилищной сферы в период 2018-2019 гг. нами был проведен опрос организаций, которые ведут свой бизнес в жилищной сфере.

Целевой аудиторией исследования выступили предприниматели, директора, представители руководящего состава и специалисты, профиль которых связан с контроллингом. География респондентов - Волгоградская область, в том числе г. Волгоград. Отправной точкой послужило исследование, проведенное специалистом отдела контроллинга продаж компании Robert Bosch Людмилой Хойссер, результаты которого были обнародованы в 2017 г. в двух публикациях в отраслевом журнале «Контроллинг» [5; 6].

Методика проведения исследования. В рамках дескриптивных исследований целью является описание какого-либо явления. В эксплоративных исследованиях используется широкий круг форм проведения исследования, в данном случае которые могут быть применены. Автором выбрана в качестве рациональной форма исследования на примере различных объектов. Таким образом, по методике Baltzer [7] исследование следует определить как дескриптивноэксплоративное.

Методы сбора данных. Для данного исследования был выбран метод количественного стандартизированного письменного опроса. К плюсам письменного опроса относятся достоверность полученных данных, малая затратность проведения и, что самое важное, предрасположенность респондентов давать максимально объективные ответы.

Подготовка и проведение опроса. Письменный опрос был проведен в форме анкетирования. Анкету составили вопросы преимущественно закрытого типа, для которых были сформулированы конкретные варианты ответов. В качестве средства коммуникации была выбрана электронная почта.

Анализ данных. В предложенном исследовании для большинства закрытых вопросов, согласно рекомендациям научной литературы, было использовано рейтинговое шкалирование из пяти шкал. Категория справа «5» обозначала наиболее сильное значение признака. Также была предоставлена шестая категория для ответа, которая обозначала «нет данных / не знаю». Открытые вопросы были проанализированы методом оценки частоты и содержания ответов.

Ограничения в исследовании. Так как сведения о контроллинге относятся зачастую к коммерческой тайне [8, с. 848], то готовность участия в научных исследованиях на эту тему в России можно оценивать как низкую, так как руководители и сотрудники организаций жилищной сферы очень чувствительно относятся к раскрытию подобных данных.

Вследствие выбранного метода сбора данных полученная выборка может проявлять искажения в сравнении с общей совокупностью организаций. Можно сделать предположение, что участники опроса более открыты к тематике кон- 
троллинга по сравнению с прочими организациями. Полученная выборка не удовлетворяет критериям репрезентативности.

Число полученных ответов. В исследовании принял участие 51 респондент. Из них 11 участников исследования либо ответили? что методы и инструменты контроллинга в их бизнесе не применяются, либо обозначили другие причины своего неучастия в опросе. Из 40 полученных анкет три были заполнены не до конца. Таким образом, число анкет для полного анализа равняется 37. Кроме того, стоит отметить, что на различные вопросы было получено различное количество ответов. Таким образом, при анализе ответов в каждом случае бралось в расчет, на каком количестве ответов основаны данные.

\section{Результаты исследования:}

Tuпы предприятий. Участников опроса попросили произвести распределение предприятий-участников опроса малые, средние и крупные предприятия согласно собственному пониманию этих категорий. Из общего числа участников $(N=40)$ наибольшее число организаций $(N=23)$ было отнесено самими респондентами к малому бизнесу, 13 организаций было отнесено к средним и два - к крупным. Два участника не обозначили тип своего бизнеса. Дальнейший анализ ответов базируется на данном распределении организаций по типам самими участниками опроса.

Должность участников опроса. Участников опроса попросили указать их должность. Из общего числа респондентов, давших ответы на этот вопрос, большинство отвечающих $(N=21)$ занимает руководящую должность в опрашиваемых организациях. Среди сотрудников неруководящих позиций наиболее часто принимали участие в опросе $(N=7)$ работники отделов бухгалтерии и финансово-экономических подразделений. Таким образом, наибольшая часть участников относится либо к работникам на руководящих позициях (53\%), либо к специалистам из бухгалтерии или же финансово-экономических департаментов (18\%). Исходя из этого, можно сделать предположение, что вследствие занимаемых должностей участники опроса достаточно квалифицированы для принятия участия в опросе на тему контроллинга.

Правовая форма. По вопросу относительно правовой формы ответило большинство участников $(N=25)$ из числа респондентов, ответивших на этот вопрос, что они работают в обществах с ограниченной ответственностью. На втором месте находятся $(N=4)$ открытые (публичные) акционерные общества. Третье место $(N=3)$ занимают ответы участников закрытых акционерных обществ. Кроме того, в опросе приняли участие по три респондента из товариществ, индивидуальных предпринимателей и прочих правовых форм.

Год создания организачии. На вопрос относительно года создания организации было получено 35 ответов. При анализе данных они были разделены на три категории. К первой категории отнесена одна крупная организация, основанная между 1990 и 2000 гг. Ко второй категории (год основания между 2001 и 2010 гг.) относится пятнадцать субъектов бизнеса. Абсолютное большинство организаций $(N=22)$ были созданы в 2011-2018 гг.

Количество сотрудников. Вопрос относительно количества сотрудников, занятых в компаниях - участниках опроса, был поставлен в открытой форме. При этом были получены данные от 37 респондентов. Для анализа количества со- 

организациях жилищной сферы

трудников был произведен расчет медианных значений для малых, средних и крупных организаций. В организациях, которые характеризуют себя как малые, медианное значение числа сотрудников соответствует 14. В организациях, которые относят себя к среднему бизнесу, медианное значение количества занятых равно 265 человек. На тех же предприятиях, которые отнесли себя к крупным, медианное значение числа сотрудников достигает 1000 человек.

Годовой оборот до налогообложения. При формулировке этого вопроса было произведено разделение субъектов предпринимательства на мелкие (до 400 млн р.), средние (от 400 млн до 1 млрд р.) и крупные (свыше 1 млрд р.), согласно закону «О развитии малого и среднего предпринимательства в Российской Федерации». На этот вопрос было получено 37 ответов.

Большая часть (76\%) обследованных представителей бизнеса имеет годовой оборот до 400 млн р. Около $21 \%$ опрошенных организаций относятся ко второй категории, и оставшиеся 3\% - к третьей категории. Анализ показал, что большая часть организаций малого бизнеса относятся к категории «до 400 млн р.», преобладающее число средних предприятий относятся к категории «от 400 млн до 1 млрд р.», а большинство крупных субъектов предпринимательства указали третью категорию - «свыше 1 млрд р.». Такое распределение организаций соответствует в целом определению субъектов малого и среднего бизнеса, представленную российским законодательством в части «годовой оборот».

Понимание категории «контроллинг». Здесь респонденты должны были сформулировать понимание категории «контроллинг», которое сформировалось в их организации. Были получены ответы от представителей 36 компаний (рис. 1). Формулировка вопроса позволяла выбрать более одного варианта ответа.

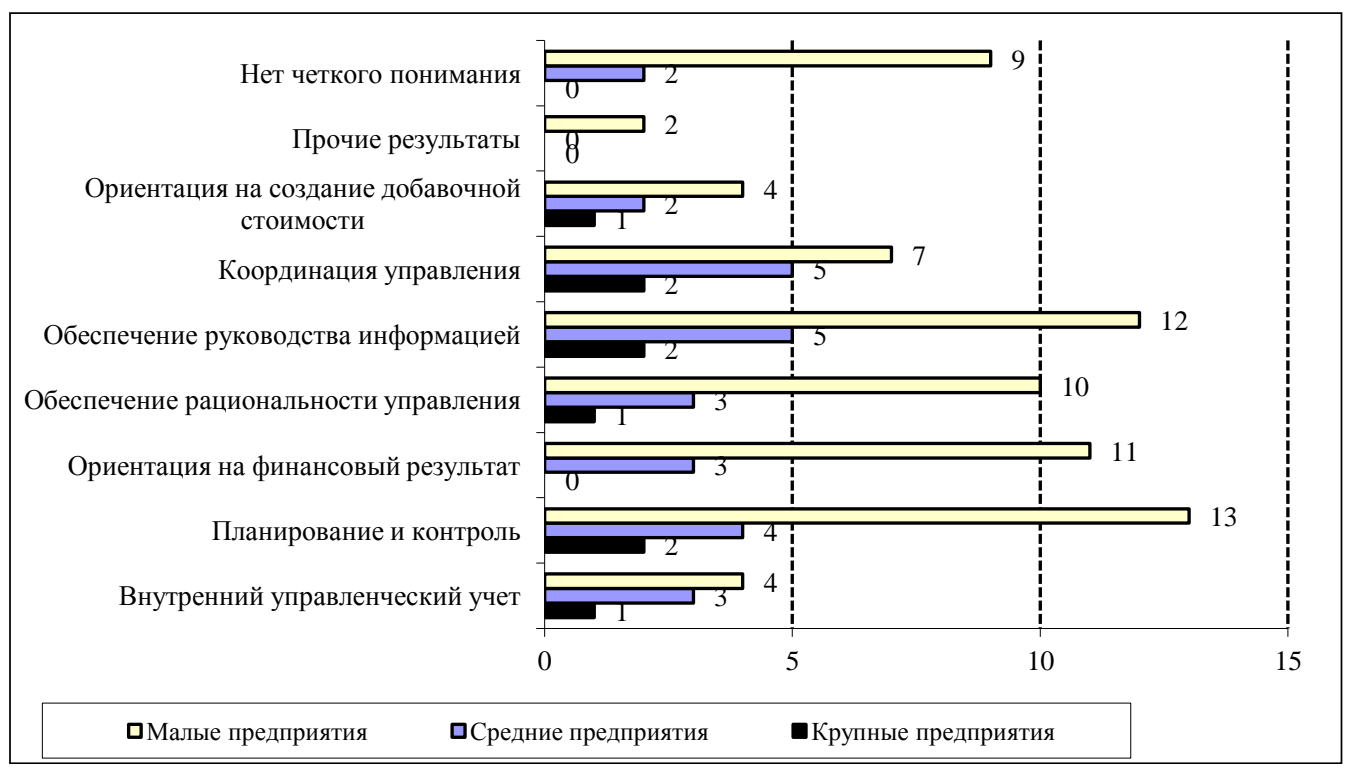

Рис. 1. Понимание контроллинга участниками опроса

\footnotetext{
${ }^{1}$ О развитии малого и среднего предпринимательства в Российской Федерации: федеральный закон от 24.07.2007 г. № 209-Ф3.
} 
Каждый анкетируемый выбрал в среднем 3,5 концептуальных подхода к пониманию контроллинга, среди которых на долю представителей малого, среднего и крупного предпринимательства пришлось, соответственно, 3, 3,8 и 4,5. Респондентами предприятий с необозначенным типом организации было указано в среднем две концепции.

Здесь большей части опрошенных $(N=25)$ присуще узкое восприятие контроллинга в виде внутреннего управленческого учета. Контроль, планирование и обеспечение руководящего состава информацией для принятия управленческих решений были наиболее часто встречающимися подходами к трактовке контроллинга. Концепция ориентации бизнеса на генерацию добавочной стоимости как более современный взгляд на вопрос была выявлена лишь у семи респондентов. 11 представителей бизнеса затруднились с четкой формулировкой категории контроллинга. При этом двое анкетируемых нашли возможным дать иную трактовку, отличную от предложенных в вариантах ответов. А именно: бюджетное планирование, теория конкурнетного доминирования на рынке.

\section{Структурная перспектива контроллинга:}

Функиии контроллинга. Представители предпринимательских структур имели возможность по аналогии с предыдущем вопросом из числа предложенных вариантов выбрать несколько, которые описывают их восприятие функционала контроллинга, а также место, которое они занимают в их бизнесе (рис. 2). Применительно к представителям средних компаний большинством видится предназначение контроллинга в планировании, контроле, координации и обеспечении руководящего состава организации информацией.

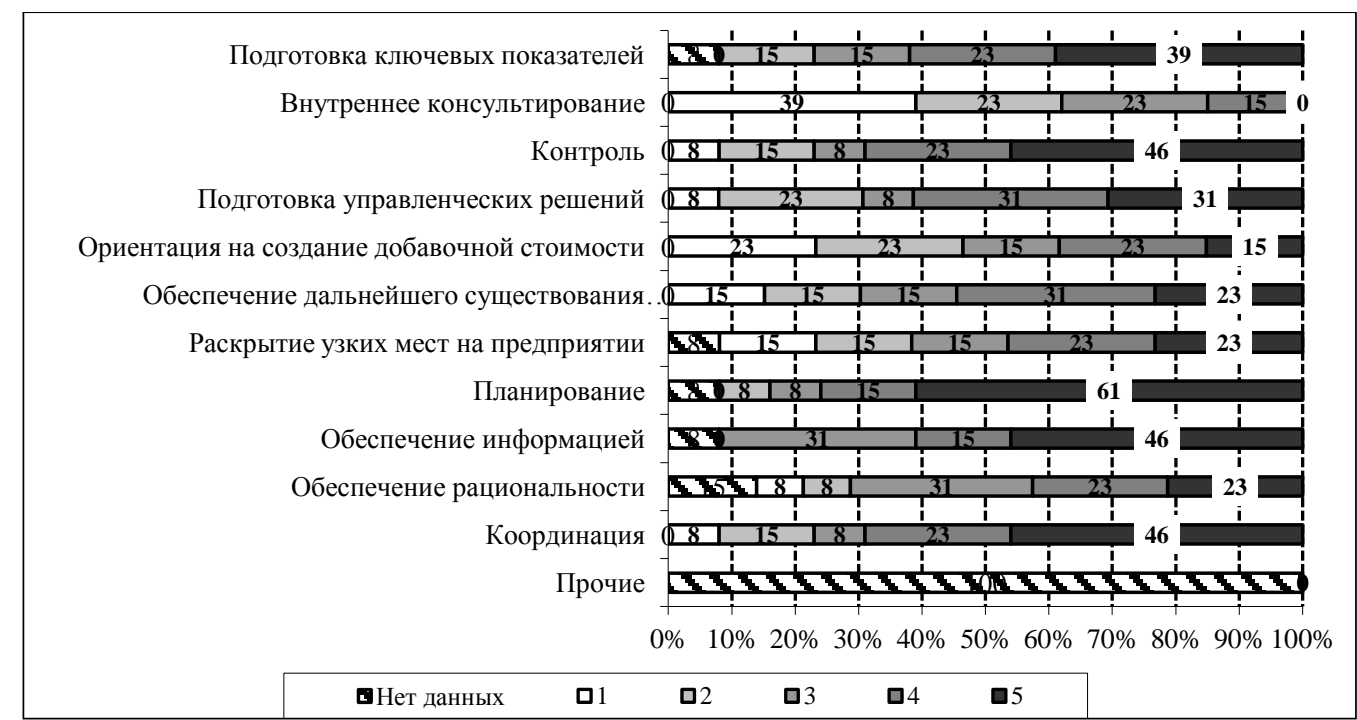

Рис. 2. Функции контроллинга

Задачи и инструменты контроллинга. В рамках этого вопроса анкетируемым был представлен список вариантов ответа, который был сформирован из числа наиболее известных, широко описанных в научной литературе и активно приме- 
P. Р. Мавлютов. К вопросу оценки потенциала повышения эффективности управления в организациях жилищной сферы

няемых на практике [9-11]. Кроме того, не исключалась возможность сформулировать свой собственный ответ, который выходил за пределы сформулированных вариантов (рис. 3).

Представители среднего бизнеса применяют все задачи и инструменты, однако в наибольшей степени находит применение формирование годовой бухгалтерской и финансовой отчетности, системы ключевых показателей, информационные системы для поддержки управленческой деятельности. Собственные варианты ответа респондентами сформулированы не были.

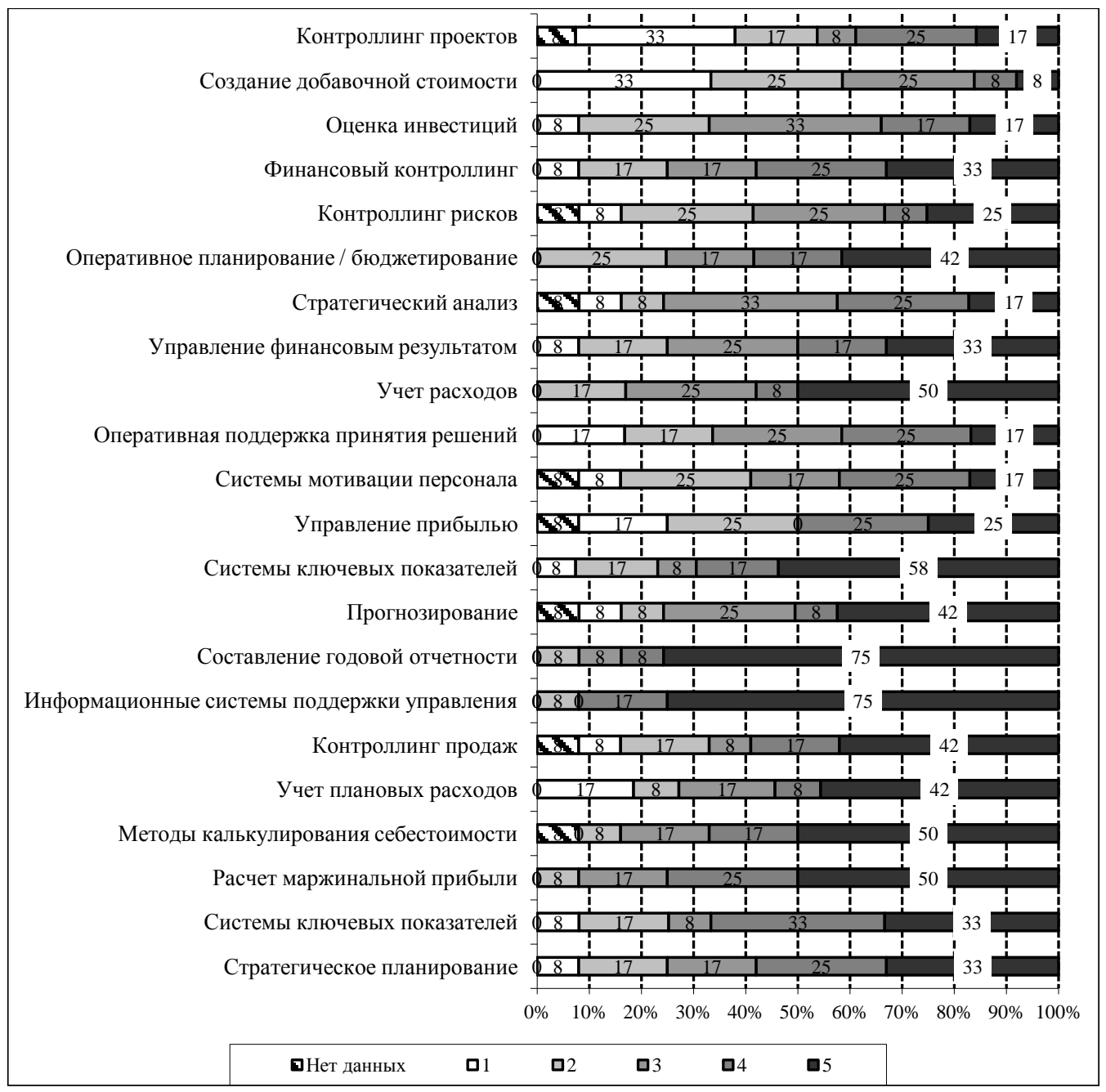

Рис. 3. Частота использования задач и инструментов контроллинга

Наличие отдела контроллинга. Данный вопрос не ставил цель выявить структурные подразделения, которые бы в своем названии содержали слово «контроллинг». Из числа полученных ответов (35) представители лишь пяти организаций дали утвердительный ответ. Далее следовал уточняющий вопрос, призванный 
выяснить год создания означенного подразделения. Во всех пяти случаях это произошло после 2005 г.: в 2005-2010 гг. подобные отделы вошли в состав трех организаций, а после 2010 г. - еще двух.

Далее респондентами были перечислены структурные подразделения или конкретные сотрудники, занимающие определенные должности, которые выполняют функционал, раскрывающий сущность контроллинга. Формулировка вопроса была открытой, подразумевающей формирование своего ответа. Допускалась возможность дать несколько ответов. Из числа опрошенных 35 дали ответ (рис. 4). Был выявлен широкий спектр вариантов ответа.

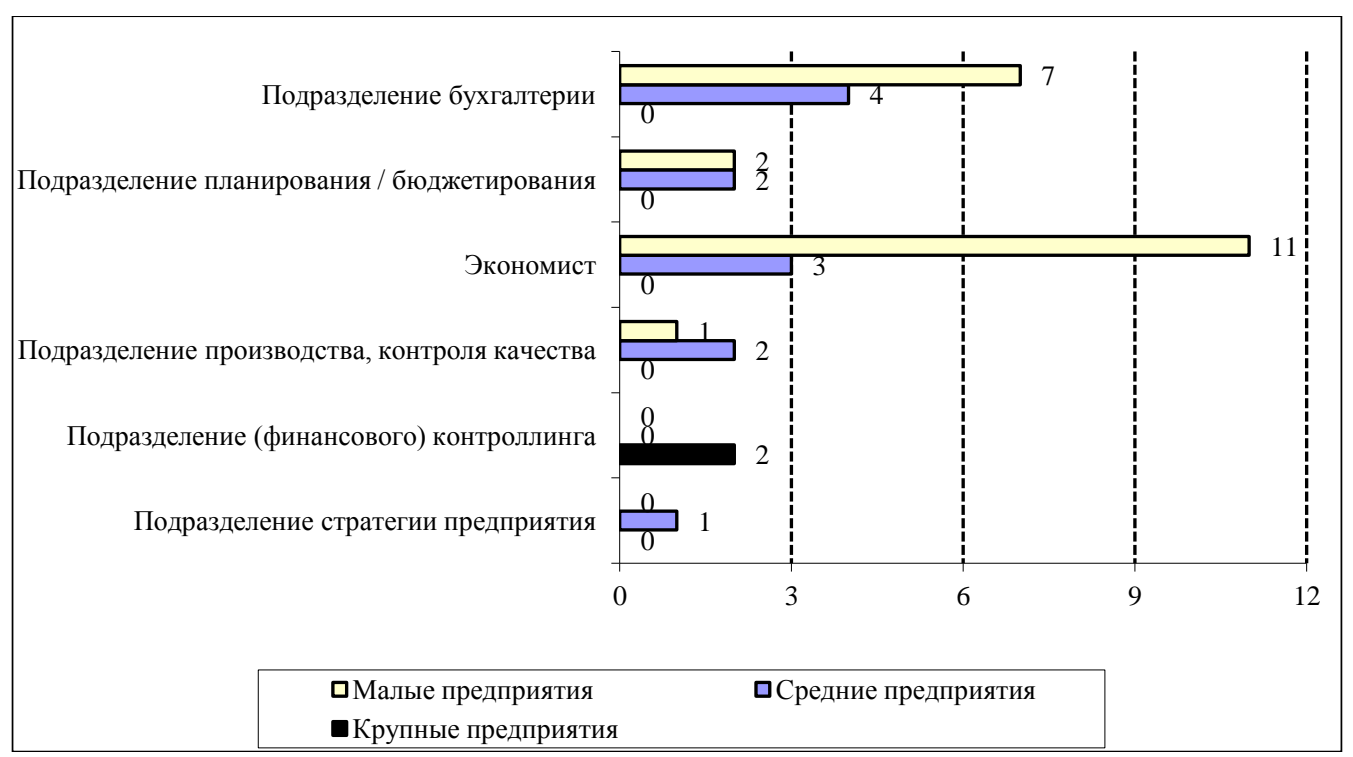

Рис. 4. Выполнение функций и задач контроллинга подразделениями

Применительно к представителям малого и среднего бизнеса в большинстве случаев функционал контроллинга возлагается на подразделение бухгалтерии, далее следовал экономист. На обоих крупных предприятиях структурное подразделение контроллинга (в том числе финансового) несет функционал рассматриваемого вида деятельности.

Подводя итоги, следует отметить, что в российских организациях жилищной сферы распространены различные концепции понимания контроллинга. При этом доминирует традиционное, узкое всприятие контроллинга. Современное же восприятие в качестве механизма, обеспечивающего генерацию добавочной стоимости, удалось выявить у малого количества респондентов.

Российское предпринимательство, осуществляющее свою деятельность в жилищной сфере, контроллингу присваивает классические функции, а современные (например, поддержание рационального управления) нашли малую реализацию. Среди прочих результатов следует выделить преобладание обязательных инструментов контроллинга (годовая финансовая и бухгалтерская отчетность), или же оперативных. В качестве отрадного момента выявлено частое применение информационных систем в целях осуществления поддержки управления бизне- 
сом. Но это скорее результат общей цифровизации экономики России как неотъемлемой части мирового хозяйства.

Лишь малое число исследованных субъектов жилищной сферы имеет в своем составе подразделение или отдел контроллинга. Большинство предприятий малого и среднего бизнеса выстроило управленческую деятельность таким образом, что функционал, инструментарий контроллинга возложен на подразделение бухгалтерии или же экономиста.

Таким образом, на текущий момент представителями предпринимательства, осуществляющими свою деятельность в жилищной сфере, еще не претворен в жизнь потенциал повышения эффективности управления, обеспечиваемый контроллингом. Лишь в малом числе субъектов бизнеса нашли свою реализацию отбельные элементы этой концепции. Вместе с тем системное управление как воспроизводством, так и эксплуатацией объектов жилого назначения, жилищной инфраструктуры в современных условиях невозможно без полномасштабного применения аппарата контроллинга.

\section{Литература} $109 \mathrm{p}$.

1. Becker, W. Controlling: Konzepte, Methoden und Instrumente, 5. Aufl., Bamberg, 2009.

2. Боброва М. В. Стратегическое управление предприятием на основе применения концепции контроллинга // Вестник Московского государственного областного университета. Сер. Экономика. 2017. № 3. С. 26-30.

3. Николаева А. Б., Халикова Н. А. Контроллинг как инструмент управления промышленным предприятием // Фундаментальная наука и технологии - перспективные разработки: материалы XIV Междунар. науч.-практ. конф. Норт-Чарлстон, 2018. С. 109114.

4. Павленков М. Н., Кемайкин Н. К. Инструменты контроллинга повышения качества управления в сфере жилищно-коммунального хозяйства // Вестник Московского государственного областного университета. Сер. Экономика. 2013. № 4. С. 82-88.

5. Хойссре Л. Контроллинг в среднем бизнесе в России: результаты исследования (часть 1) // Контроллинг. 2017. № 64. С. 72-79.

6. Хойссре Л. Контроллинг в средлнем бизнесе в России: результаты исследования (часть 2) // Контроллинг. 2017. № 65. С. 72-78.

7. Baltzer B. Einsatz und Erfolg von Controlling-Instrumenten. Wiesbaden, 2013. 317 p.

8. Мавлютов Р. Р. Чубенко О. В. Оценка экономической целесообразности внедрения и модернизации системы контроллинга на российских предприятиях // Финансовая экономика. 2018. № 6. С. 847-849.

9. Вебер Ю., Шеффер У. Введение в контроллинг: пер. с нем. / под ред. и с предисл. С. Г. Фалько. М.: Объединение контроллеров, 2014. 416 с.

10. Фольмут Х. Й. Инструменты контроллинга от А до Я: пер. с нем. / под ред. М. Л. Лукашевича и Е. Н.Тихоненковой. М.: Финансы и статистика, 2003. 288 с

11. Hahn D. PuK: Planung und Kontrolle, Planungs- und Kontrollsysteme, Planungs- und Kontrollrechnung. Springer-Verlag, Heidelberg. 2013. 442 p. 
ON ASSESSING THE POTENTIAL FOR IMPROVING MANAGEMENT EFFICIENCY IN HOUSING SECTOR

Ramil R. Mavlyutov

Cand. Sci. (Econ.), A/Prof.,

Volgograd State Technical University,

28 Lenina Prospect, Volgograd 400005, Russia

ramil-2002@mail.ru

Abstract. Entrepreneurial activity in housing sector is characterized by low management efficiency. Moreover, management efficiency is one the most important aspects of sustainable business development. In Western practice, it is widely accepted that that controlling is an important aspect of successful management. In Russia today there is a lack of theoretical and practical knowledge about controlling in housing sector. The article presents the results of a study aimed at identifying the current state of controlling as a basis for assessing the potential for improving management efficiency in housing sector. The objects of the study are enterprises of Volgograd Oblast, including its administrative center. It has been found that controlling in its modern understanding is not widespread, only a small number of business entities implement some elements of controlling. At the same time, controlling functions are mainly laid upon the related departments.

Keywords: organization; housing sector; entrepreneurial activity; business; controlling; control; efficiency; potential; opinion poll; information.

Статья поступила в редакцию 22.10.2020; одобрена после рецензирования 30.10.2020; принята к публикации 30.10.2020. 